DeVillar and Jiang: U.S. Student Teachers in Belize, China and Mexico

\begin{tabular}{l|l} 
IN S T I T U T E & $\begin{array}{l}\text { INDIA, CHINA AND AMERICA INSTITUTE } \\
\text { 1549, CLARMONT ROAD, SUITE 202 } \\
\text { WWW.ICAINSTITUTE.ORG }\end{array}$
\end{tabular}

U.S. Student Teachers in Belize, China and Mexico: Patterns of Cultural, Professional, and Character Development

Robert A. DeVillar \& Binbin Jiang Journal of Emerging Knowledge on Emerging Markets
Volume 1 Issue 1
Not 


\title{
U.S. Student Teachers in Belize, China and Mexico: Patterns of Cultural, Professional, and Character Development
}

\author{
Robert A. DeVillar, Ph.D. \\ Professor, Bagwell College of Education \\ Kennesaw State University \\ Binbin Jiang, Ed.D. \\ Associate Professor, Bagwell College of Education \\ Kennesaw State University \\ Journal of Emerging Knowledge on Emerging Markets \\ Volume 1 Issue 1 \\ November 2009
}

\section{Introduction}

\section{Problem}

he level of knowledge, pedagogical skills and dispositions that pre-service and practicing teachers have regarding students from cultures different from their own is generally weak and even cause for feelings of professional inadequacy. Thus, knowledge, skills and dispositions in the area of student cultural diversity are of major importance, particularly as these factors can relate to teachers' effectiveness, or lack thereof, in communicating with and understanding the students they teach (Catalogna, Greene \& Zirkel, 1981; Dee, 2005; Kea, Trent, \& Davis, 2002; Neal, Mccray, WebbJohnson, \& Bridgest, 2003; Rueda, Au \& Choi, 2004; Sheets, 1996). This research-based 
principle is particularly relevant as teacher ethnicity in the United States will remain predominately white over the next few decades, even as student ethnicity will continue its dramatic path of reflecting diverse ethnic and racial backgrounds other than white (Causey, Thomas, \& Armento, 2000). Students designated as minority, for example, comprised $41 \%$, or 22,500,000, (U.S. Census Bureau, 2008) of the estimated fifty-five million students enrolled in elementary and secondary schools (U.S. Census Bureau, 2006). Additionally, in 2006, 23\% (12,650,000) of all students had at least 1 parent who was foreign-born, and 5\%, or 2,275,000, of all students were themselves foreign-born (U. S. Census Bureau, 2008). Nearly 11 million (20\%) of the students spoke a language other than English at home, 7.8 million (71\%) of whom spoke Spanish (U.S. Census Bureau, 2008).

In stark contrast to the above data, the percentage of the nearly 3.5 million (U.S. Census Bureau, 2008) public elementary and secondary teachers in the United States designated as white in 2004 was $83 \%$ (U.S. Census Bureau, 2004). Since the 1990s, the expectation of heightened competence of knowledge, skills and disposition has extended also to school administrative leaders (Hafner, 2005) - a professional group that is also overwhelmingly white. Ninety-five percent (95\%) of public school superintendents in the United States, for example, were reported as white in 2000 (Björk \& Keedy, 2001), as were 82\% of public school principals in the 1999-2000 school year (Gates, Ringel, \& Santibañez, 2003).

The continued dramatic growth of Hispanic, Asian, and other designated minority populations, in contrast to the teacher and administrative characteristics described above, drive school enrollments. Minority student enrollments in 2003, for example, accounted for $25.6 \%$ of all public school preK-12 enrollments in the Midwest; for 35.2\% in the Northeast; for $46.4 \%$ in the South; and for $54.1 \%$ in the West (U.S. Department of Commerce, Bureau of the Census statistics, reported by Peterson, 2005). The percentages in each case other than that of the South were nearly double that of 1972 enrollment figures: $12.5 \%, 18.6 \%$, $30.3 \%$, and $54.1 \%$, respectively (Peterson, 2005). Moreover, minority groups will account for some $65 \%$ of the U.S. population growth in the two-decade period of 2000-2020 (Hodgkinson, 2000/2001).

While improvements in particular academic indicators have been made over the past three decades by Hispanic, African American, and other designated minority students, overall a significant academic gap persists (Whitehurst, 2005) and drop-out rates among these groups remain disproportionately high (Fry, 2003). Population projections indicate that students from Hispanic, Asian, African American, and Multiracial categories will form the overwhelming increase in enrollment figures, as the non-Hispanic White population continues to decline relative to the replacement level of its particular category (NHW) while other groups contribute. The disparity is transformational in terms of race and ethnicity, particularly as the Non-Hispanic White population, from 2030 to 2050, "would contribute nothing to the Nation's population growth," and, conversely, "after 2020 the Hispanic population is projected to add more people to the United States every year than would all other race/ethnic groups combined" (Bureau of the Census, 1996). 
Educational researchers have criticized teacher education programs in the United States for insufficiently preparing teachers to work with diverse student populations (Cochran-Smith, Davis, \& Fries, 2004; Gay, 2002; Ladson-Billings, 1999). In addition, the adequacy of these programs to address global issues has also been questioned (Jennings, 2006). Professional associations also have realized the importance of preparing teacher candidates to teach diverse students in schools. The National Council for the Accreditation of Teacher Education (NCATE), for example, has stipulated Standard 4 as Diversity, which requires, in part, that teacher education programs demonstrate evidence that their teacher candidates have been engaged in experiences with diverse student populations and that they can "apply proficiencies related to diversity" (NCATE, 2008).

Thus, teachers - as front-line professional educators - must learn to understand the students whom they teach, as well as aspects of their language use and cultural backgrounds (Cushner \& Brennan, 2007) and behaviors. First-hand contact in a school setting within a representative culture is a direct way of providing a solid foundation for NCATE's diversity requirement, and complements multicultural and related course work taken within the teacher preparation program prior to the international student-teacher experience. McAllister and Irvine (2000) assert two fundamental points that guide the current authors' investigation. First, that research remains "inconsistent" and "scant" regarding the "process by which teachers develop a cross-cultural competence that enables them effectively to teach diverse students in their classrooms;" second, that "teaching training and professional development models do not adequately develop the type of cross-cultural competence... deemed essential for teachers of diverse students" (McAllister \& Irvine, 2000:3-4).

\section{Theoretical Framework}

More than one hundred universities and colleges in the United States offer student teaching abroad opportunities through participation in a larger consortium or through developing their own programs (Quezada, 2004). Many teacher education institutions realize the need to change the contrasting reality of increasing number of minority students in schools and the lack of substantive intercultural experiences and skills among the majority of teachers (Cushner, McClelland, \& Safford, 2000; Melnick \& Zeichner, 1998). Student teaching abroad experiences have served as a catalyst for beginning teachers to start on a path of learning about another culture and people through direct interaction with that culture and people (Mahon \& Cushner, 2002; Mahon \& Cushner, 2007), concurrently with their guided professional development experience. The academic literature generated to describe and understand the value and impact of this experience is generally based on students' personal reflections and surveys, program evaluations, and perceptions by on-site educators within the particular international contexts (Baker, 2000; Bryan \& Sprague, 1997; Cushner \& Mahon, 2002; Mahon \& Cushner, 2007; Stachowski, Richardson, and Henderson, 2003). Three general elements characterize the student teacher growth and development process: instructional pedagogy, learning about oneself, and an appreciation and understanding of 
multiculturalism (Bryan \& Sprague, 1997; Clement \& Outlaw, 2002; Cushner \& Mahon, 2002; Stachowski \& Visconti, 1997; Stachowski \& Chleb, 1998; Stachowski, Richardson, \& Henderson, 2003). Research (Wang, 2001, cited in Tang \& Choi, 2004) has found that interaction between teachers and student teachers may differ in length and frequency, in location, and in topics according to the country. Also, differential effects on the development of student teachers' competence may occur due to variation in instructional and supervisory practices and socio-professional contexts within different countries (Tang $\&$ Choi, 2004). Additionally, Roose (2001) reports that cross-cultural education internships powerfully influence the beginning teacher in six areas: (1) the effects of culture on schooling; (2) understanding school as a culture; (3) understanding students and learning; (4) curriculum; (5) professional development; and (6) attraction to difference.

The current study presented in this paper supports, refines, and adds to the above literature. It supports the literature by demonstrating general and positive effects on student teachers associated with their respective international experiences in Asia and Latin America. It refines the above literature by rigorously addressing student teacher abroad experiences within (1) three developing country contexts on two continents, (2) the different school settings (public and private) in which they were placed, and (3) the effect-both general and contrastive - of the respective contexts and school settings in terms of student teachers' cultural-, professional-, and character-development. Finally, the study applies a rigorous research approach based on Glaserian grounded theory (Glaser, 1992; Glaser \& Straus, 1967). Grounded Theory may be defined as a "set of rigorous research procedures leading to the emergence of conceptual categories... related to each other as a theoretical explanation of the action(s) that continually resolves the main concern of the participants in a substantive area" (Grounded Theory Institute, 2008). The present analysis restricts itself to the emergence stage.

\section{Objectives of Study}

The objectives of this comparative study were to apply a modified form of Glaserian grounded theory to determine the effect of student teaching abroad experiences in Belize, China and Mexico, and, in so doing, generate subsequent questions from the emerged categories. Thus, the authors generated questions 2 through 4 after they first analyzed, coded and categorized data associated with question 1.

Q1. What are the type and degree of patterns that emerge from a student teaching abroad experience as evinced by the content analysis of student teachers' individual electronic journals?

Q2. What is the impact of student teaching in Belize, China and Mexico on participating student teachers relative to their: professional development, self-development and cultural responsiveness?

Q3. What are the similarities in the above three impact areas on the participating student teachers in Belize, China and Mexico? 
Q4. What are the differences in the three impact areas on the participating student teachers in Belize, China and Mexico?

\section{Methodology}

The research is primarily qualitative in nature, complemented by descriptive statistics, and spans a three-year period (2005-2008). Content analyses of weekly student teacher journals, pre- and post-attitudinal collaborating teacher assessments, pre- and post-self-assessment surveys, interviews, and site visits comprise the methods designed and applied. Thirteen (13) white, non-Hispanic student teachers, twelve of whom were women, participated in one of three semester-long international student teaching experiences. In Belize (fall 2005), four participants specialized in elementary education and three specialized in secondary education; in China (spring 2006), two participants specialized in elementary education and one (male) in secondary education; and in Mexico (spring 2008), one participant specialized in elementary education and two in secondary education. In Belize, student teachers were assigned as follows: two, to a public school in the city of San Ignacio; two, to a public school in Belmopan; and, two, to a private school and one to a public school in Belize City. In China, all three student teachers were assigned to a private school in Guangzhou. In Mexico, all three student teachers were assigned to a private school in Mexico City.

The data gathered for analysis include student teacher-generated weekly electronic journals, open-ended questionnaires, program evaluation forms, and on-site observations by the researchers. Specifically, weekly e-journal reflections of two elementary and two middle grades participants in Belize, two elementary and one middle school participants in China and one elementary and two secondary participants were gathered, coded and analyzed. In addition, a 6-item open-ended questionnaire was administered prior to departure to, and upon their return from, their respective international contexts. Finally, student teachers completed a program evaluation form by the after each group's return to the United States. On-site observations by the researchers of the student teachers within their respective instructional contexts complemented the above data gathering methods. The data were analyzed utilizing content analysis and descriptive statistics. The researchers utilized the coding instrument developed from their analysis of the Belize student teachers' weekly journals of fall 2005 in which they identified emergent patterns consisting of nine (9) themes and sixty (60) topics (DeVillar, Jiang, \& Bryan, 2006).

\section{Results of Data Analysis}

\section{Journal Reflections}

The initial analysis of journals by U.S. student teachers in Belize by DeVillar and Jiang (DeVillar, Jiang, \& Bryan, 2006) produced sixty categories and nine themes emerged from the data corpus. DeVillar and Jiang operationally defined each theme and category in accordance with its contextualized presence in the journal entries (see Appendix A for 
description of the following nine themes: Instructional Engagement, Professional Development Characteristics, Personal or External Instructional Assessment, Emotional Preparedness, Comparative Schooling Awareness, Perceived Role, Cultural Responsiveness, Perceived Student Attributes, and Student Teacher Observations).

Belize. In the analysis of the Belize journals, five of the nine themes emerged in greater frequency than the other four-a phenomenon common to all the Belize student teacher journals: Instructional Engagement, Personal or External Instructional Assessment, Professional Development Characteristic, Cultural Responsiveness, and Emotional Preparedness. Within Instructional Assessment, at least three of the four participants discussed two topics more frequently than they did any other of the ten topics in this thematic area: Limited Instructional Preparedness and Instructional Productivity. The former topic (I-Prep) emerged as one of the most salient by all four participants from four different schools; the latter topic (I-Prod), by three of the four participants. Within the theme Professional Development Characteristics, two topics emerged as most frequently discussed by at least three of the four participants: Professional Insight and Professional Commitment. Within the theme Cultural Responsiveness, Cultural Engagement was the topic that occurred most frequently in the journals of three of the four Belizean participants. Within the theme Emotional Preparedness, the multifaceted topic of Determination, Confidence, Enthusiasm or Hope occurred with greater frequently in the journals of three of the four Belizean participants. Within the theme Instructional Engagement, Student Instructional Assessment was the topic that occurred most frequently in the journals of three of the four Belizean participants, while that of Subject Matter Instruction occurred most frequently in the journals of all four Belizean student teachers.

In summary, two of the five common themes relate to instruction (Instructional Assessment and Instructional Engagement), focusing on the assessment of the student teachers' preparedness and productivity in the classroom, as well as their assessment of student learning, and on the multiple aspects of their subject matter instruction. The theme of Professional Development Characteristics relates to the professional growth and development of the student teachers. Analysis of e-journals indicates two substantive findings regarding student teachers within this thematic area. First, they gained particular insight into their role as professionals through the process of interacting with collaborating teachers, students, and parents. Second, they demonstrated enhanced professional commitment to the students despite references to their challenging contexts, which included lack of instructional materials and reliable and easily accessible electronic technology, and classrooms of students from diverse language and cultural backgrounds. Topics within the theme of Emotional Preparedness occurred frequently among three of the four participants. Student teachers tended to share the following three qualities: (a) determination or confidence, or both, to overcome the challenges they were facing in their international context; (b) enthusiasm toward working with the diverse students and collaborating teachers in their respective classroom and school settings; and (c) hope for success within their teaching and learning contexts. 
China. The researchers' analysis of e-journals submitted by student teachers in China followed the identical methodological framework and yielded the following results. Within the theme of Instructional Engagement, all three student teachers discussed the topic of subject matter instruction more frequently than they did any of the ten other topics. Within the theme of Emotional Preparedness, all three student teachers discussed the collective topic of Determination, Confidence, Enthusiasm or Hope more frequently than they did the other topics (that is, Personal Doubt, Reservation, Anxiety or Pessimism and Personal Emotional Ambiguity). Within the theme of Professional Development Characteristics, all three student teachers discussed the topic of professional insight with a higher frequency than they did the other seven topics. Within the theme of Cultural Responsiveness, all three student teachers discussed the topic of cultural engagement with a higher frequency than they did the other twelve topics.

Mexico. The researchers' analysis of e-journals submitted by student teachers in Mexico followed the identical methodological framework as Belize and China and yielded the following results. Within the theme of Instructional Engagement, all three student teachers in Mexico discussed the topic of subject matter instruction as the other two groups did. In addition, two of the secondary student teachers also frequently discussed the topics of Student Instructional Assessment, Student Response to Student Teachers and Student Behavior Management. Within the theme of Professional Development Characteristics, all three of the student teachers in Mexico discussed the topic of Professional Insight more frequently than any other topic. Within the theme of Instructional Assessment, the two secondary student teachers discussed the topics of Complete Instructional Preparedness and Complete Instructional Productivity more frequently than any other topic. Within the theme of Emotional Preparedness, all three student teachers discussed the collective topic of Determination, Confidence, Enthusiasm or Hope more frequently than they did the other topics as the Belize and China groups. Within the theme of Cultural Responsiveness, two of the three student teachers discussed the topic of cultural engagement with a higher frequency than they did the other twelve topics. In addition to the above five themes, two of the three student teachers discussed the topics of Participatory Student Teacher Observations and Collaborating Teacher Support, which indicated their keen observation of the collaborating teachers and the classroom culture as well as their appreciation of the support given from their collaborating teachers.

A Tri-Country Comparison. Comparing the most frequently discussed topics and themes that emerged from the e-journals of the student teachers abroad in Belize, China and Mexico, four themes were common to both groups: Instructional Engagement, Professional Development Characteristics, Emotional Preparedness, and Cultural Responsiveness. In contrast to student teachers abroad in China, however, one additional theme (Instructional Assessment) and three additional topics (limited instructional preparedness, limited instructional productivity, and professional commitment) emerged with substantive frequency in the e-journals of the Belize student teachers and Mexico student teachers. In addition, the student teachers in Mexico discussed an additional theme (Student Teacher 
Observation) and two topics (participatory student teacher observation and collaborating teacher support) within this same theme.

Thus, the e-journals of the China group contained four themes with one topic embedded in each theme and differed from e-journals of student teachers in the two other country contexts. The Belize student teacher group's e-journals contained five themes common to all four student teachers and eight topics common to at least three of the four participants. Those of the Mexico student teacher group contained six themes and eleven topics.

\section{End of Program Questionnaire Findings}

Belize and China student teachers completed a 6-item questionnaire after their respective student teaching abroad experiences. A summary of the results includes the following. With respect to the anticipated effect of the student teacher abroad experience on employability, 5 out of 7 student teachers, including all three student teachers in China, considered that it would have a positive effect on their employability, while the remaining student teacher responses indicated no pattern.

In terms of anticipated change in attitudes towards their future students, the majority of the student teachers from Belize (5), and all three student teachers in the Mexico group, responded that they would experience a positive change; all three student teachers from the China group responded that there would be no change in their attitudes.

Regarding the effect of the student teaching abroad on the way they will teach, all students in the Belize and China and Mexico groups responded positively. However, the Belize student teachers commented on their enhanced sensitivity to students' backgrounds and needs as well as enhanced creativity in lesson planning and adaptability with respect to resources. The China group's comments focused only on enhanced sensitivity to students' backgrounds and using their own international experience to inspire their students to "dream big and travel the world too" [ST1GZ.PS].

In response to their perceived enhanced instructional flexibility due to their respective student teaching abroad experiences, all three groups responded positively. Furthermore, each member of the China group identified an individual professional quality associated with instructional flexibility: enhanced adaptability, open-mindedness, and tolerance.

Relative to the question of increased curricular choices due to the international student teaching experience, six of the 7 Belize student teachers and all three student teachers in Mexico responded positively, while all three of the China group responded negatively. Additionally, the Belize student teachers commented positively on the value of integrating technology, culture, and realia in instruction, and having an enhanced sense of instructional creativity and the Mexico student teachers emphasized on global perspective and knowledge. In response to the question of attitude change toward the use of a second language in teaching, four of the seven student teachers to Belize and all student teachers who went to China and Mexico responded positively. Three participants in the Belize group and two participants in the Mexico group responded positively to gaining an enhanced 
motivation to learn a second language, while one in the Belize group responded positively relative to attaining a heightened respect for bilingual speakers and one in the Mexico group emphasized more understanding of the challenges of second language learners. The China group's comments ranged from the ability to relate to parents better and having more patience and understanding, to having attained more focus in the presentation of lessons.

In summary, with respect to similarities, all members of three groups considered that the international teaching experience had had a positive impact on their teaching and increased their instructional flexibility. In addition, 10 of the 13 participants -4 of the Belizean group and all 6 of the China and Mexico group-claimed a positive attitude change toward second language use in their classroom and 9 (5 from Belize; 3 from China and 1 from Mexico), a positive effect on employability. With respect to having experienced an anticipated attitude change toward students or toward increased curricular choices due to their student teaching abroad experiences, most of the Belizean group (5 and 6, respectively) and all three student teachers in Mexico responded positively while the entire China group (3) responded negatively.

\section{Overall Similarities and Differences: Belize, China and Mexico Student Teacher Groups}

We base the following intergroup comparison on multiple data sources, including the researchers' on-site observations of student teachers' teaching experiences, student teachers' end of the program evaluations, questionnaires, and their journals.

Commonalities: Three major similarities stand out in the analysis of the data-specifically, language of instruction (English), contrastive international context, and length of time student teaching in K-12 schools. In all three countries, Belize, China and Mexico, the student teachers used English, their native language, as the language of their instruction, although the students in these countries spoke other languages as well as English.

In Belize, even though English is the official language of the country, other languages such as Belize Creole (a linguistic rule-governed amalgam of English, Native American and African languages that is native to Belize and widely spoken), Garífuna, Maya and Spanish co-exist and compete with the official standard version of English. In China, Mandarin Chinese is the official and most widespread dialect of Chinese, although tens of millions of mainland Chinese speak one of the other four recognized dialects in China-Wu, Min, Yue and Hakka - as their first language, each of which is mutually unintelligible from Mandarin. In addition, there are over 120 minority languages in China, which account for 83 million speakers, or 6.7 percent, of the Chinese population (Huang Xiang, 2003).

In Mexico, Spanish is the national language spoken, although approximately 7.2 million people $(7.0 \%)$ speak one of the 62 indigenous languages, all of which are nationally recognized (Hamel, 2008). Nevertheless, English was the language of instruction at the schools in which the student teachers taught in all three countries. 
A second similarity among the three groups of student teachers was the singularity of their respective international context. Aside from language and dialect variations, there were substantive cultural and demographic distinctions immediately in evidence with which the student teachers had to contend and that contrasted starkly with their home culture and demographics. These distinctions were racial, ethnic, social, culinary, religious, political, environmental, and architectural, among others, and added complexity, anxiousness and tentativeness to the initial interactions and confidence of the student teachers.

A third commonality was that all three groups of student teachers spent the same length of time-12 weeks - in each of their K-12 school contexts. Despite the above similarities, our analysis of data indicated major differences in the two groups' contexts, experiences and results.

Differences: We categorized the differences into ten types (see Table 1): 1) school, 2) level of teaching, 3) student demographics, 4) collaborating teachers' demographics, 5)

instructional resources, 6) student teacher accommodations, 7) student teacher cultural experiences, 8) cultural characteristics, and 9) range of most frequently discussed topics.

\section{Findings and Discussion}

Preliminary interpretations of findings are four-fold:

1) Student teachers in all three countries acquired professional and personal knowledge, skills, and dispositions. This finding was consistent with Quezada's (2004) literature review on student teaching abroad, particularly in instructional pedagogy, learning about oneself, and an authentic appreciation of multiculturalism or a different culture (Bryan \& Sprague, 1997; Clement \& Outlaw, 2002; Cushner \& Mahon, 2002; Mahon \& Cushner, 2007; Stachowski \& Visconti, 1997; Stachowski \& Chleb, 1998; Stachowski, Richardson, \& Henderson, 2003). With respect to instructional pedagogy, student teachers emphasized instructional engagement; that is, the manner in which they interacted with their students in the classroom. They particularly focused on the topic of subject matter instruction-the content area or areas they were teaching - as in the case of the participants in all three countries, and student instructional assessment - that is, the student teachers' perceptions of how well their students were learning - as in the case of the participants in Belize and Mexico. The end-of-program questionnaire results indicated that all members in three groups considered that the international teaching experience had had a positive impact on their teaching and increased their instructional flexibility. Regarding the directionality of student teachers' emotional state, student teachers' journal entries emphasized a consistent state of positive emotional preparedness. As a general pattern, student teachers specified their determination, confidence, enthusiasm or hope when they encountered professional and cultural challenges in their student teaching experience. In terms of an authentic appreciation of multiculturalism or a different culture, student teachers emphasized the theme of cultural responsiveness, focusing most strongly on their engagement in the host culture. 
Moreover, most of the participants (seven of the 10 participants-four in the Belizean group and all three in the China group) asserted in their end of program questionnaire a positive attitude change toward second language use in their classroom. This finding indicates an appreciation and understanding of the value and challenge of linguistic diversity within an instructional setting and the importance of instructional pedagogy to adapt instruction to meet this challenge. Student teacher journal entries also reflected this attitudinal change, albeit in substantively distinct ways, as the two journal-entry examples below demonstrate.

I do think the experience here will be beneficial when I return. I have had to use some Spanish even if it is just one word, to communicate with my students. This will help if I am at a school with a higher percentage of Hispanic students. The hardest part is communicating with the parents who only speak Spanish. I do not know enough to carry on a conversation about a child's behavior or performance in the class. I would recommend to any teacher taking Spanish as an elective in school or classes outside of school. In order to have cooperation from the parent, a teacher must be able to communicate effectively in both English and Spanish. [STBSI.J2]

The three student teachers in China, in contrast, generally did not describe the schooling context within which they taught, perhaps due to its similarity to affluent school environments in their home state, not merely in building design, but also in student, faculty and administrator demographics, particularly the use of Standard American English. The student teachers in China generally described their cultural experiences in terms of shopping, restaurants, transportation, site seeing, and personal observations regarding the population. Culturally-related journal entries were analogous to what a tourist might note regarding one's own lack of ability upon using chop-sticks, or the sensation of being exposed to new native and foreign (French, Vietnamese, Korean) foods, or young children being allowed to relieve themselves on sidewalks or in malls. Thus, statements regarding cultural experiences that dramatically altered their way of thinking or sense of purpose were negligible, and opportunities, such as those that might enhance their professional development, remained disconnected from these same cultural experiences and offer a marked contrast to student teachers' stated connections to cultural experiences in Belize.

I leave tomorrow for Shanghai at 2pm...I am a little nervous because I have not taught college level students, since I am trained to [teach] elementary students. I know I have a gift with the little ones, but not sure about the older students. Also, I have not taught conversational English before and there is no text book to use either. However, I am really excited about the experience and the challenge... Within the last year and a half I have actually thought about becoming a college professor after teaching for awhile, so I think this will be a wonderful experience. I think it will also help teaching ESOL students...back in the U.S. classroom. Here is to a fun new adventure in China! [ST1GZ.J11]

Another related area of growth among student teachers (also exemplified in the two quotes immediately above) was manifested in their professional development, especially with 
respect to developing their own professional insights relative to teaching, cultural issues and emotional challenges.

2) The degree of learning and development of each student teacher varies based on one's academic preparedness and ability to adjust to the student teaching environment.

Nevertheless, in terms of aggregate patterns found within each country, the resulting development pattern among student teachers in Mexico and Belize manifested a more numerous and complex range of experiences and reflections expressed within journals in the form of topics and themes than was the case for the student teachers in China. This finding supports the literature regarding differential affects on participants' student teaching abroad experiences due, in part, to the variation in instructional and socio-professional settings found within different country contexts (Tang and Choi, 2004).

3) Context influences outcomes. The student teachers in Belize experienced multiple cultures and low-income/poverty conditions in their school and cultural contexts; the quote below demonstrates the effect had on a student teacher:

My students range from 7 to 10 years of age, only about 7 of them can read, many have problems identifying colors, and some come to school with no shoes on... On my way [to school], I pass houses with no roofs or windows, chickens and roosters roaming, a creek where there are always women washing clothes while their children are bathing in the same water or sometimes they are bathing in the water, and babies and children walking around with no shoes, shirts or many time naked. I think the saddest part is everyday having children stand at our school fence and ask if they can come to school to learn...it is hard to turn them away and my heart breaks for all of them. I think [that] after this experience I will be able to teach in any setting with any varieties of culture. [STBB.J3]

Their student teacher counterparts in China and Mexico, on the other hand, experienced multiple cultures in affluent schooling contexts, and had but limited and indirect exposure to low income/poverty conditions (e.g., street beggars). Thus, the Belize group of student teachers had a multicultural experience reflective of the lower socioeconomic status contexts of U.S. public schools, particularly those characterized by language and cultural diversity; in contrast, the China and Mexico student teacher groups' international schooling experiences and cultural contexts reflected private, affluent, nonsectarian schooling contexts.

4) Student teachers in all three countries reported that they had exerted a positive impact on students in their respective classrooms; however, there was more reflection in the Belizean context than within the Chinese or Mexican context on the connection between student teaching and future teaching in the United States. Student teachers echoed this connection in their responses to the end-of-program questionnaire. Specifically, with regard to the effect of the student teaching abroad experience on the way they will teach, all students in the three groups responded positively. However, the Belize student teacher group's comments exhibited a richness in elaboration and detail, stating their enhanced sensitivity to 
students' backgrounds and needs and their enhanced creativity in lesson planning and ability to adapt in the face of limited instructional resources.

\section{Conclusion}

Preliminary findings associated with student teaching abroad settings indicate that such venues can serve as a substantive step in helping institutions of higher education develop teachers to embody these new values, and enabling schools - and the students, parents, and the wider community they serve-to reap the benefits derived from the cadre of culturally responsive educators. Additionally, international contexts having similar multicultural settings to those found within U.S. public schools may be more conducive to the student teachers' learning and future practice as a teacher within the U.S. public school setting.

Reflections by student teachers in the form of electronic journals can be an important resource for identifying complex themes and related topics directly associated with the student teaching experience and the related professional, character, and cultural development of student teachers. Reflections that are natural-that is, that are not constrained by rigid predetermined criteria regarding topics to cover and formats to applyenable student teachers to engage authentically (unpredictably) as agents in their particular series of intentional acts of communication with their intended audience (Goffman, 1983). The natural reflection writing process enables student teachers to describe, grapple and interpret the student teaching experience in its broadest sense, which includes the culture and various settings and actors within it, inside and outside the specific school context. This process also enables the student teacher to share the immediate impact of an experience or range of experiences, and even to discover and predict its longer-term influence relative to one's personal, professional or cultural development in the United States. The analysis of student teachers' reflective journaling within and across cultural settings can also identify salient patterns, both within a country and among countries, relative to commonalities and differences among student teachers with respect to their multidimensional development, as well as to the degree of correspondence to U.S. school settings characterized by an increasingly diverse student body.

\section{Implications of the Study}

The study's findings may contribute to teacher educators' and educational administrators' understanding of the spate of research-informed advantages associated with international student teaching programs, thus enhancing the development of such programs and provision of such experiences to more pre-service teachers in teacher education institutions. In addition, international contexts having similar multicultural settings to those found within U.S. public schools may be more conducive to the student teachers' learning and future practice as a teacher within culturally diverse U.S. public school settings. This finding may be helpful to international staff and teacher educators in making decisions on site selection for international student teaching placements. Site selection criteria for prospective student 
teachers would entail both the anticipated value of the in-country comprehensive student teaching experience, as well as the student teachers' anticipated cultural relevance of their knowledge, skills and dispositions to their future U.S. classrooms.

\section{References}

Baker, B. R. (2000). Moving beyond our education community: Student teacher abroad. Paper presented at the annual meeting of the Association for Childhood Education International, Baltimore, MD, April, $17-20$.

Bjork, L, \& Keedy. J. (2001). Changing social context of education in the United States: Social justice and the superintendency. Journal of In-Service Education, 27, 405-427

Britton, E., Pain, L., Pimm, D., \& Raizen, S. (2003). Comprehensive teacher induction: Systems for early career learning. Dordrecht: Kluwer Academic Publishers.

Bryan, L. S., and Sprague, M. M., (1997). The effect of overseas internships on early teaching experiences. The Clearing House, 70, 199-201.

Causey, V. Thomans, C., \& Armento, B. (2000). Cutlural diversity is basically a foreign term to me: the challenges of diversity for preservice teacher education. Teaching and Teacher Education, 16, 33-45.

Clement, C., M. and Outlaw, E., M. (2002). Student teaching abroad: Learning about teaching, culture, and self. Kappa Delta Pi Record, 38(4), 180-183.

Cochran-Smith, M., Davis, D. \& Fries, K. (2004). Multicultural teacher education: Research, practice and policy. In J. A. Banks \& C. A. Banks (Eds.), Handbook of research on multicultural education ( $2^{\text {nd }}$ ed.), San Francisco: Jossey Bass, 931-975.

Cushner, K., \& Brennan, S. (2007). The value of learning to teach in another culture. In Cushner, K. and Brennan, S. (Eds.) Intercultural student teaching: A bridge to global competence. Lanham: Roweman \& Littlefield Education in partnership with the Association of Teacher Educators.

Cushner, K., McClelland, A., \& Safford, P. (2000). Human diversity in education: An integrative approach. New York: McGraw-Hill.

Cushner, K. \& Mahon, J. (2002). Overseas student teaching: Affecting personal, professional, and global competencies in an age of globalization. Journal of International Studies in Education, 6(2), 44-58.

DeVillar, R. A., Jiang, B., \& Bryan, S. (2006). The Multi-dimensional Impact of a Student Teaching Abroad Program, paper presentation, AERA, San Francisco, CA, April 7-11, 2006

Eraut, M. (1994). Developing professional knowledge and competence. London \& Washington, D.C.: Falmer Press. 
Fry, R. (2003). High school drop out rates for Latino youth. (Retrieved July 31, 2005 from ERIC Clearing house on Urban Education. ERIC No: ED482920).

Gates, S., Ringel, J., \& Santibanez. L. (2003). Who is leading our schools? An overview if school administrators and their careers. Retrieved July 30, 2005 from http://www.rand.org/publications/MR/MR1679.

Gay, G. (2002). Preparing for culturally responsive teaching. Journal of Teacher Education, 53 (2), 106116

Glaser, B. G. (1992). Discovery of grounded theory analysis: Emergence vs. forcing. Mill Valley, CA: Sociology Press.

Glaser, B. G., \& Strauss, A. L. (1967). The discovery of grounded theory: Strategies for qualitative research. Piscataway, NJ: Aldine Transaction.

Goffman, E. (1981). Forms of Talk. Philadelphia, PA: University of Pennsylvania Press, second printing, 1983.

Grounded Theory Institute Website (2008). What is grounded theory? Retrieved September 5, 2008, from http://www.groundedtheory.org/.

Haberman, M. (2002). Achieving "High Quality" in the selection, preparation and retention of teachers. Printed in EducationNews.Org. Retrieved August 2, 2005 fromhttp://www.educationnews.org/ACHIEVINGHIGHQUALITYINTHESELECTIONPREPARATION ANDRETENTIONOFTEACHERS.htm

Hafner, M. ( 2005, April ). Preparing school leaders to ensure equity and work toward social justice: An exploratory study of leadership dispositions. Paper presented at the annual meeting of the American Educational Research Association, Montreal, Quebec.

Hamel, R. E. (2008). Indigenous language policy and education in Mexico. In May, S. and Hornberger, N. H. (Eds.), Encyclopedia of language and education, 2nd Edition, Volume 1: Language Policy and Political Issues in Education, 301-313. New York: Springer Science+Business Media LLC.

Hodgkinson, H. (2000/2001). Educational demographics: What teachers should know. Educational Leadership, 58, 6-11.

Jennings, C. (April 2006). Teacher education: Building a foundation for the global workforce. AACTE Briefs, 27 (4).

Ladson-Billings, G. (1999). Preparing teachers for diverse student populations. Review of Research in Education, 24, 211-248.

Mahon, J. \& Cushner, K. (2007). The impact of overseas student teaching on personal and professional development. In Cushner, K. and Brennan, S. (Eds.) Intercultural student teaching: A bridge to global competence. Lanham: Roweman \& Littlefield Education in partnership with the Association of Teacher Educators. 
Mahon, J. \& Cushner, K. (2002). The overseas student teaching experience: Creating optimal culture learning. Multicultural Perspectives, 4(3), 3-6.

Martines, D. (March 2005). Teacher Perceptions of Multicultural Issues in School Settings. The Qualitative Report, 10 (1), 1-20.

McAllister, G. \& Irvine, J. J. (2000). Cross-Cultural Competency and Multicultural Teacher Education. Review of Educational Research, 70 (1), 3-24.

McNally, J., Cope, P., Inglis, B., \& Stronach, I. (1997). The student teacher in school: Conditions for development. Teaching and Teacher Education, 13 (5), 485-498.

Melnick, S. L., \& Zeichner, K. M. (1998). Teacher education's responsibility to address diversity issues: Enhancing institutional capacity. Theory Into Practice, 37 (2), 62-69.

NCATE. (2008). National Council for Accreditation of Teacher Education: NCATE Unit Standards. Retrieved July 28, 2008 from http://www.ncate.org/public/unitStandards Rubrics. asp?ch=4

Peterson, K. (2005). Diversity fuels student enrollment boom. Retrieved July 30, 2005 from http://www.stateline.org/live/ ViewPage.action? siteNodeId $=136 \&$ languageId $=1 \&$ contentId $=35088$

Quezada, R. (2004). Beyond educational tourism: Lessons learned while student teaching abroad. International Education Journal, 5(4), 458-465.

Roose, D. (2001). White teachers' learning about diversity and "otherness": The effects of undergraduate international education internships on subsequent teaching practices, Equity and Excellence in Education, 34(1), 43-49.

Slick, S. K. (1998). The university supervisor: A disenfranchised outsider. Teaching and Teacher Education, 14(8), 821-834.

Stachowski, L., Richardson, W. J., and Henderson, M. (2003). Student teachers report on the influence of cultural values on classroom practices and community involvement: Perspectives from the Navajo reservation and from abroad. The Teacher Educator, 39(1), 52-63.

Stachowski, L. and Chleb, J. (1998). Foreign educators provide feedback for the improvement of international student teaching experiences. Action in Teacher Education, 19(4), 119-130.

Stachowski, L. and Visconti, V. (1997). Adaptations for success: U.S. student teachers living and teaching abroad. International Education, 26, 5-20.

Tang, S. Y. F. (2003). Challenge and support: The dynamics of student teachers' professional learning in the field experience. Teaching and Teacher Education, 19(5), 483-498.

Tang, S. \& Choi, P. (2004). The Development of personal, intercultural and professional competence in international field experience in initial teacher education. Asia Pacific Education Review, 2004, Vol. 5, No. $1,50-63$. 
U.S. Census Bureau (2008). The Statistical Abstract. (2008). Table 230. Public elementary and secondary schools-Summary: 1980-2005. Retrieved July 27, 2008 from http://www.cencus.gov/compendia/statas/tables/08s0239.pdf

U.S. Census Bureau (2008). Facts for Features: Back to school 2008-2009. Retrieved July 27, 2008 from http://www.census.gov/Press-Release/www/releases/

archives/facts_for_features_special_editions/012084.html

U.S. Census Bureau (2006). Facts for Features: Back to school 2006-2007. Retrieved July 27, 2008 from http://www.census.gov/Press-Release/www/releases/archives/

facts_for_features_special_editions/007108.html

U.S. Census Bureau (2004). Facts for Features: Special Edition,

Teacher Appreciation Week (May 2-8). Retrieved July 27, 2008 from http://www.census.gov/Press-

Release/www/releases/archives/facts_for_features_special_editions/001737.html

U.S. Census Bureau (2004). Population profile of the United States. Retrieved July 27, 2008 from http://www.census.gov/population/www/popo-profile/natproj.html

Wang, J. (2001). Contexts of mentoring and opportunities for learning to teach: a comparative study of mentoring practice. Teaching and Teacher Education, 17(1), 51-73.

Whitehurst, G. (2005). National assessment of educational progress. Retrieved July 31, 2005 from http://nces.ed.gov/commissioner/remarks2005/7_14_2005.asp

Yasin, S. (1999). The supply and demand of elementary and secondary school teachers in the United States. Retrieved July 31, 2005/July 28, 2008 from ERIC Clearinghouse on Teaching and Teacher Education Washington DC, ERIC No: ED436529, http://www.ericdigests.org/2000-3/demand.htm. 